\title{
Study on Water Resources Optimal Allocation of Irrigation District and Irrigation Decision Support System
}

\author{
Liang Zhang ${ }^{1,2}$, Daoxi $\mathrm{Li}^{2}$, and Xiaoyu $\mathrm{An}^{2}$ \\ ${ }^{1}$ Zhengzhou University, Zhenzhou, P. R. China \\ ${ }^{2}$ North China University of Water Resources and Electric Power, Zhenzhou, P. R. China \\ zhangliang@ncwu.edu.cn
}

\begin{abstract}
This paper develops the system of optimal allocation of water resources in irrigation district and irrigation decision-making support which integrates technologies of decision-making support, information management, information search and so on. It has the multi-function of water production function calculation, crop water requirement calculation, water resources optimal allocation and real-time amending the decision of irrigation. This system integrates the experience of experts with computer technology to guide farmers to irrigate in a proper way, for which the limited water resources can produce a marked effect on irrigation, so irrigation district management and efficiency are improved.
\end{abstract}

Keywords: Optimal allocation of water resources, irrigation district, watersaving irrigation, decision support system.

\section{Introduction}

As we all know, agriculture is the main consumer of water. At present, agriculture of China faces water shortage, for agricultural water has been diverted by industrial water and domestic water, meanwhile, serious waste of agricultural water, lack of corollary irrigation facilities, sever defacement of trenches and long-term flooding irrigation lower the effective availability of irrigation water, as a result, valuable water can't work in due course, therefore, we must vigorously advocate water-saving irrigation to construct a water-saving agriculture[1]. The key of water saving in agricultural irrigation is management[2], so management is meaningful in this area. There have been many studies about water-saving irrigation in China, but most of them are about hardware of facilities of water-saving irrigation, few about software such as water resources and optimal allocation[3]. To apply computer technology to irrigation district management will make full use of the valuable experience of experts in water conservancy with the help of modern technology to make a significant contribution to the improvement of irrigation district management, for which study on optimal allocation of water resources in irrigation district and irrigation decision supporting system is significant ${ }^{1}$.

1 Endowed by national science and technology supporting project (2007BAD88B02) (2006BAD11B09-2). 


\section{A Brief Review of DSS Applied in Water Resource Management}

Decision support system (DSS) is a form of information system development, which is firstly pointed out by Scott Norton in 1971. It is an information system based on computer to support decision-making action, and a kind of interactive software aiming at assistant decision-making of application problems such as planning, management, scheduling, combat command and scheme optimization. With the developing of computer technology and the introducing of expert system and artificial intelligent technology, DSS technology is combined with other various technologies and has been developed into expert system and intelligent decision support system.

DSS has been applied to water resource management since 1980s. Raboh.R.Reiter, J.and Gaschnig. J(1982) [4] presented HYDRO system to supply a similar parameter to watershed feature parameter which is selected by hydrological experts with great efforts and be applied to estimating the effect of different hydrological factors. Palmer. R. N and Tull, R. M(1987) [5], Palmer, P.N and Holmesk. J(1988) [6] have successively invented SID and WMS related to expert system of drought management plan, these two systems are similar in function and can be used for predicting and displaying the information related to drought management plan. Based on discrimination of the similar degrees of present drought and past drought, according to their experience, users can make decision of water quantity optimal distribution with linear programming model. Based on drought degree, Raman.H[7] has built up expert system with linear programming model to conduct crop optimization to guide drought scheduling decision that irrigation system will face in the future. CADSM[8] model is an expert system functioning as decision support, which can simulate crop yield and crop water-needing process to predict the effect of soil salinity and moisture on yield to supply users with water distribution plan of different canal systems.

The software of water resource management decision support system in China is developed and applied relatively late. Wenbing Weng et al. (1992)[9] develope decision support system of water resource planning of JIng-Jin-Tang area (Beijing, Tianjin and Tanggu), this system has the function of expert knowledge and consultation. Jianxin Xu(1999)[3] developes regional water resource planning and irrigation water-saving irrigation development of Expert system through analyzing main factors of irrigation technology choice in irrigation area and introducing semi-structured and multi-objected optimum technique. Based on Penman's formula, Zhouping Shangguan(2001)[10] combines with present agronomy knowledge of northwest arid area, model and experience to conduct system integration to build up intelligent decision support system by using artificial intelligent technology. Hujun Shang(2002)[11] points out developing model combined with data-based system, expert system and computer simulation through researching water-saving irrigation prediction and decision management database system.

However, the studies mentioned above are mainly theoretical, exploratory or expert consulting; most results of them haven't been perfect and practical yet. So far the study on water resource management and agricultural irrigation decision support system in China still exists in the exploring stage. 


\section{Introduction of the System}

The developing and operating of water resources optimal allocation of irrigation district and irrigation decision support system in this study are based on Chinese Windows platform, main framework of this system software is compiled with Borland Delphi 7.0, using Delphi, some numerical computation modules are developed by data interface with the method of Matlab, the program of assistant decision database of water-saving irrigation is designed by Paradox 7.0 formula.

This system is a system which has a database, a data management system and model calculation program library. It has a brief human-computer interface and a capability of reasoning and outputting the result of words and charts. Fig.1 indicates the system structure.

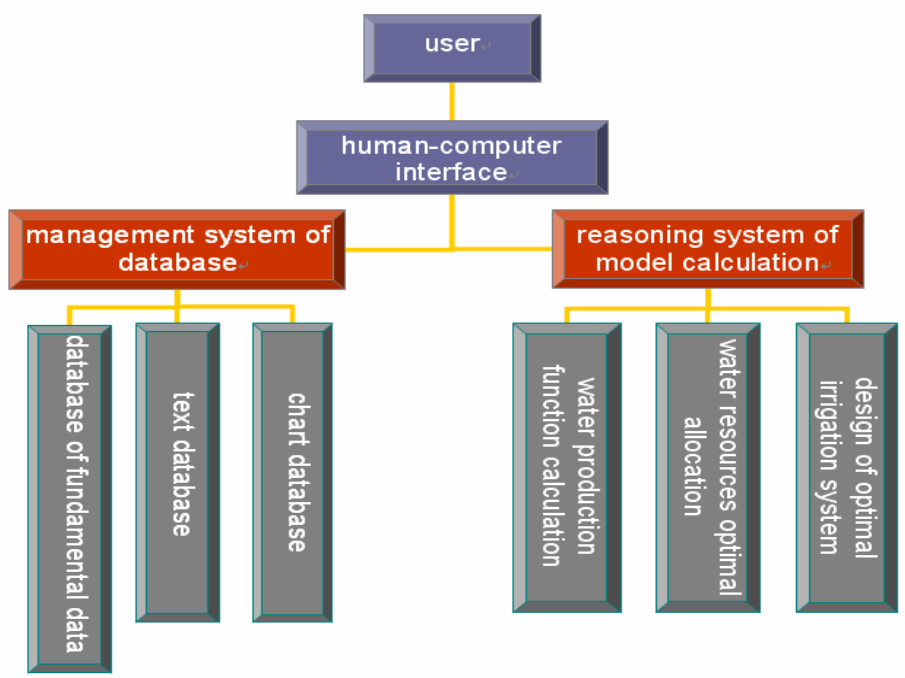

Fig. 1. System structure

The general function of the management system of database is to memorize, search, collate, collect, and survey all sorts of data. Meanwhile, this system can also supply necessary data for related results; this system can be divided into three parts in general, as follow: (1) Database of fundamental data, which deposits all the basic data of irrigation districts including the proportion of them, crop planting, social economy condition of them, population information of them and so on. (2) Text database, which deposits the data in form of text, mainly including calculation result memorized in form of text which calculated by working model. (3) Chart database, which mainly deposits all sorts of charts of system, and can output the calculation result in form of charts according to the requests of the customers, by the way, the output information will be made more intuitionistic. 
The reasoning system of model calculation contains three parts: (1) Crop water

production function calculation; (2) Water resources optimal allocation of irrigation districts; (3) design of optimal irrigation system under the condition of insufficient irrigation. These subparts not only can work independently but also can work together as a whole.

\section{Key Technology of Model}

\subsection{The Constitution of Water Production Function and Parameters Calculation}

\subsubsection{Analysis of Water Production Function}

In order to conduct water resources optimal allocation to achieve the highest efficiency, we must set up the function of irrigation amount and yield of all sorts of crops in different hydrological years and make use of indirect relationship between irrigation amount and yield to get the function of irrigation amount and net benefit.

In real course of solving, the function formula of irrigation amount - crop yield in different hydrological years is constituted firstly as usual, and then irrigation amount-irrigation benefit function as follow is constituted by using the relationship between input and output. By derivation of it, the change rate of benefit of crop in every unit of irrigation amount can be achieved, that is marginal benefit. According to marginal benefit, efficient irrigation method of limited water resources for crop can be inferred.

The formula of water production function usually has the linear relationship, quadratic parabola relationship, power exponential function and so on. Based on a great amount of research result, and analysis of the experiment data of past irrigation experiments, the author thinks that as for the plain areas of the Yellow River, the Huaihe River and the Haihe River in China, water production function had usually better appear to be a quadratic parabola.

\subsubsection{The Solving Principle of Water Production Function}

Supposing the basic formula as follow:

$$
Y=a x^{2}+b x+c
$$

In the formula above, $\mathrm{Y}$ stands for yield per unit area $\left(\mathrm{kg} / \mathrm{hm}^{2}\right) ; \mathrm{X}$ stands for water consumption per unit area $\left(\mathrm{m}^{3} / \mathrm{hm}^{2}\right) ; \mathrm{a}, \mathrm{b}$ and $\mathrm{c}$ are regression analysis coefficient which can be achieved with the least square method.

The function relationship between irrigation amount and crop yield increase can be educed by deducting the yield without irrigation from the crop yield in all. According to the formula below[12], the increasing production benefit and irrigation benefit of all sorts of crops corresponding to different irrigation amount in different hydrological years can be educed.

$$
B_{i}=K\left(Y_{i}-Y_{0}\right)-C
$$


In the formula, $\mathrm{B}_{\mathrm{i}}$ represents increasing production benefit $\left(\mathrm{Yuan} / \mathrm{hm}^{2}\right)$; $\mathrm{K}$ represents the price of crops (Yuan $/ \mathrm{kg}$ ); Yi stands for crop yields of different irrigation amount in unit area ; Yo stands for crop yield without irrigation in unit area; $\mathrm{C}$ represents related water charge for different irrigation amount.

Irrigation benefit can be educed by the formula as follow:

$$
B_{\varepsilon_{i}}=\varepsilon B_{i}
$$

In the formula above, $\mathrm{B}_{\varepsilon \mathrm{i}}$ stands for irrigation benefit $\left(\mathrm{Yuan} / \mathrm{hm}^{2}\right)$; $\varepsilon$ represents the sharing coefficient of irrigation factor. As usual, winter wheat takes $\varepsilon=0.45$, other crops take $\varepsilon=0.4$.

\subsection{Calculation of Water Resources Optimal Allocation of Irrigation District}

This paper mainly studies how to distribute limited water resources in a proper way to achieve the maximum total benefit of an irrigation district without changing the agricultural planting structure. Dynamic programming method is adopted here to study water resources optimal allocation[13], mathematic model should be constituted firstly, and the model includes five parts as follow:

(1) Phase variant, as usual each crop is regarded as a water consumer, that's a phase. As for an irrigation district with $\mathrm{N}$ sorts of crops, it has $\mathrm{N}$ phase variants, that's to say phase variant $\mathrm{n}=1,2, \ldots, \mathrm{N}$.

(2) Condition variant and decision-making variant, condition variant is water quantity can be distributed in each phase, which is qn for short; decision-making variant is the water quantity supplied for every crop in each phase, which is xn for short.

(3) System equation, according to the relationship between condition variant and decision-making variant, system equation can be reckoned, as follow:

$$
\mathrm{q}_{\mathrm{n}}+1=\mathrm{q}_{\mathrm{n}}-\mathrm{x}_{\mathrm{n}}
$$

(4) Objective function: supposing $\mathrm{F}(\mathrm{w})$ is maximum net benefit achieved by contributing total water $\mathrm{W}$ to $\mathrm{N}$ sorts of crops, then:

$$
F(\mathrm{w})=\max \left\{\sum_{i=1}^{N} r_{n}\left(x_{n}\right)\right\}
$$

(5) Constraint condition

a. the sum of water quantities for every crop can't exceed total water resources.

b. the water quantity $x_{n}$ for crop of $n$ can't exceed the minimum among the largest passing water capacity of trench, available water of water source and total water resource, and it can't be negative. 
c. $\mathrm{q}_{\mathrm{n}}(\mathrm{n}=1,2, \ldots, \mathrm{N})$ can't exceed the water quantity which is possibly supplied for $\mathrm{n}$ sorts of crops at the same time by every phase.

(6) Initial condition : $\mathrm{q}_{1}=\mathrm{W}$

Making use of the constrain conditions, and initial condition above, we can constitute dynamic programme model of water resources optimal allocation, and solve the mathematic model above by the way of inverted sequence recurrence, the recursive equation as follow:

$$
\begin{gathered}
f_{n}\left(q_{n}\right)=\max _{\substack{0 \leq x_{n} \leq q_{n} \\
0 \leq q_{n} \leq W^{n}}}\left\{r_{n}\left(x_{n}\right) f_{n+1}\left(q_{n+1}\right)\right\} \quad(n=1,2, \ldots, N-1) \\
f_{N}(q)=\max \left\{r_{N}\left(x_{N}\right)\right\} \quad n=N, 0 \leq x_{N} \leq q_{N}
\end{gathered}
$$

\subsection{The Design of Optimal Irrigation System (Optimal Allocation of Water for Every Growing Stage of Crops)}

Under the condition of limited water and water in short supplying, it's impossible to completely meet the need of water for crops in each stage and the whole course of their growing, in this way, proper irrigation should be insufficient irrigation which is to realize water optimal allocation among different crops and different growing phases of them to make sure water supply of every crop in its water requirement critical period and reduce water supply in water requirement uncritical period, by this way, what we seek for is the highest total yield in the whole irrigation district under the condition of limited water resources.

Under the condition of limited water supply, for water supply of each crop usually exists in the left hand of the point in which water supply can realize the maximum benefit, the optimal irrigation course design of a single crop this paper aims at the highest yield. With Jensen's model, we can design irrigation course, the model as follow:

$$
F=\max \left(\frac{Y}{Y_{m}}\right)=\max \prod_{i=1}^{n}\left(\frac{E T_{i}}{E T_{m i}}\right)^{\lambda_{i}}
$$

There are several rules we should obey to conduct system design of optimal irrigation:

(1) Real quantity of water supply should be based on the quantity of optimal allocation water supply.

(2) Under the condition of insufficient irrigation, moisture content of planned soil wetting zone of a single crop is controlled between field capacity and wilting coefficient.

(3) The design of irrigation quota must accord with the reality of agricultural production and deep percolation mustn't occur. 
(4) The system design must make good use of rain water, and irrigation mustn't result in extra-runoff of rain water.

(5) The design of irrigation course must meet the water supply constraint and the constraint of water conveyance capacity[14].

In the course of designing optimal plan, we take the way of simulation model with the basic principle of water balance equation to fulfill the irrigation decision-making course by compiling computer decision support system software. Firstly, the necessary basic material such as effective rainfall, field capacity, initial soil water content is input, in this way, computer can automatically calculate the real water requirement in every growing stage of crops in the background. Secondly, irrigating water time, quantity of irrigating water, surplus water and the yield ratio of crops under the condition of sufficient irrigation and their real yield can be forecasted after inputting limited irrigating water quota of crops in their growing stages and the bound of the lowest moisture rate by human-computer interface, and then based on the primary irrigation project, the highest rate of real yield of crops and their yield under the condition of sufficient irrigation can be achieved by making sure the modified indexes from the changing course chart of soil moisture rate of planning moisture layer and modifying designing project repeatedly. If there are some changes in the course of real rainfall, rainfall course, limited irrigating water quota of crops in their growing stages and the lower bound of the lowest moisture rate can be carried out real-time modification to achieve the highest yield crops. This method is applicable to all the irrigating course design of crops under different rainfall frequency.

\section{Example for Software Application}

We take an irrigation district of Daming County Hebei Province as an example, control area of this irrigation district is $73 \mathrm{~km}^{2}$, irrigation area of it is $4667 \mathrm{hm}^{2}$, the main crops and their growing rates are respectively winter wheat $65.5 \%$, spring cotton $11 \%$, spring corn $23.5 \%$, summer cotton $10 \%$, and summer corn $55 \%$, multiple cropping index 1.655. Total water supply of surface water in this irrigation district is $1650 \times 104 \mathrm{~m}^{3}$ in the year of $\mathrm{P}=75 \%$.

\subsection{Optimal Allocation of Irrigation Water Resources}

Firstly water production function of crops can be solved with local irrigation experiment material. Secondly the total water supply is dispersed as a calculation unit of $10 \times 10^{4} \mathrm{~m}^{3}$, and then based on irrigation benefits solved of different crops, by dynamic planning mathematic model which has already been built, with the method of inverted sequence recursive, water optimal allocation calculation is carried out step by step. At last, optimal allocation water quantity of every crop and total benefit of irrigation of the typical district in the year of $\mathrm{P}=75 \%$. Fig. 2 shows the results of irrigation benefits of different crops and benefits of pre unit water. 


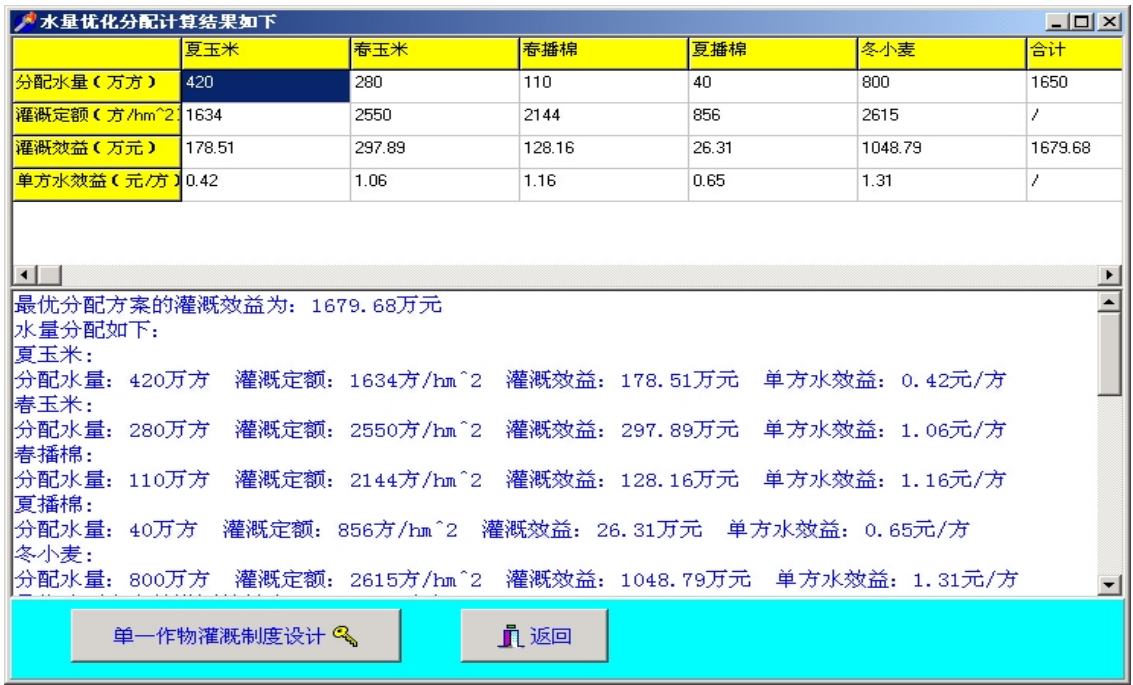

Fig. 2. Result of optimal distribution of irrigation water resources

\subsection{Carrying Out Irrigation System Design of the Single Crop}

According to irrigation quota of each crop under the condition of total water optimal allocation, by using water balance equation at the time in which water content of

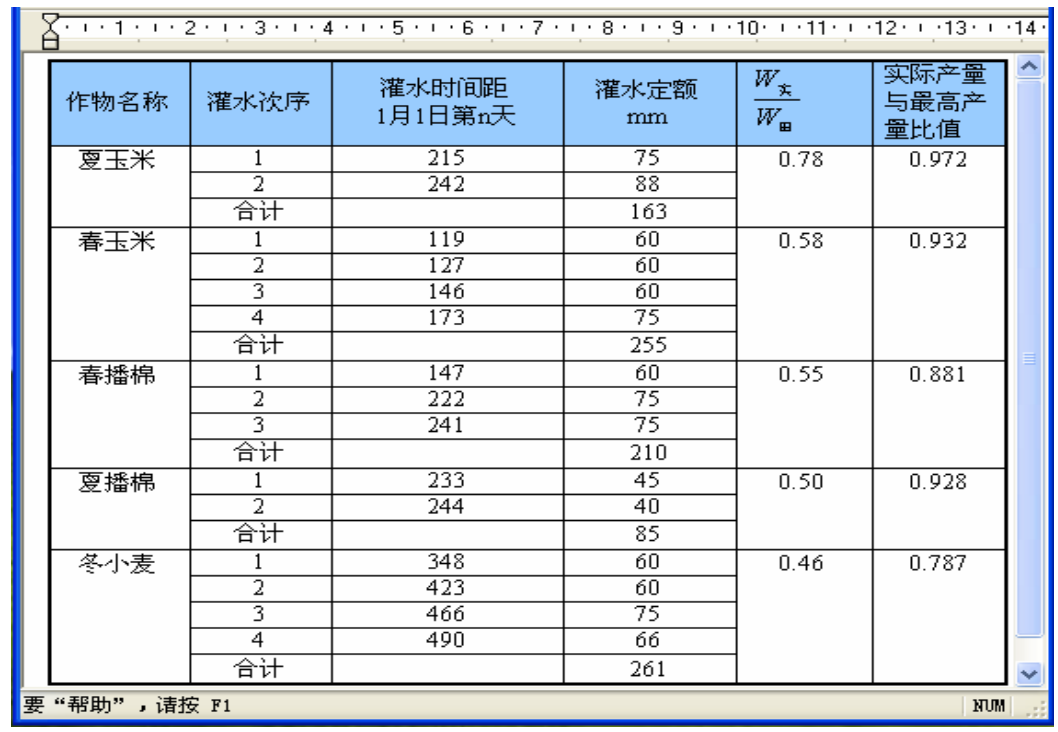

Fig. 3. Result of irrigation system 
planned moisture layer is less than 0.7 time of field water-holding ratio, under the condition of insufficient water supply for crops, the quantity of water consumption of the crops is modified. After three times trial calculation, irrigating water quota and irrigating time of irrigation district can be made out as fig. 3 .

\subsection{Result Analysis}

From the optimal allocation of water quantity of each crop and the result of optimal irrigation system, we can find that among all the crops, the total water quantity distributed to winter wheat (冬小麦)and total irrigation quota (灌浇定额) of it are the largest for its benefit of per unit water (单方水效益) is the highest, while those of summer cotton（夏播棉） and summer corn（夏玉米） are smaller and lower for the water-needed course of these crops happens to meet raining course, the yields of these crops are relatively high without irrigation. All the crops can be irrigated in their critical water-needed phase, so this optimal irrigation decision-making course with the system design is reasonable.

\section{Conclusion}

This paper applies DSS and technique to water resource optimization of irrigation district and irrigation decision and management to establish water resource optimization and irrigation decision support system that includes water production function calculation, water resources optimal allocation of irrigation districts and optimal irrigation decision model. In the course of programming, we take a method of mutually contacting with each other and relative independence from each other. Through our experimenting with example, this method of programming is proved to be right and this program is practical and effective. Meanwhile, it is proved that the technique of DSS has wide application prospect in water-saving agriculture, which can improve the scientific and technological content in the field of water-saving agriculture to make irrigation management take a new step.

\section{References}

1. Shi, Y., Lu, L., et al.: Chinese agricultural water demand and wate-saving and efficient agriculture. 中国农业需水与节水高效农业建设. China's Sustainable Development Strategy of Water Resources Report, vol. 4. China WaterPower Press. Beijing (2001)

2. Xu., J., Shen, J.: Modern technology in the field of application of water-saving irrigation. 现 代科技在节水灌溉领域中的应用. Science Technology and Dialectical, Xi' an (3) (1999)

3. Xu, J.: Expert System of Water Resources Evaluation and High-effective Irrigation in the Irrigation Area. 灌区水资源评价及节水高效灌溉专家系统. Ph.D thesis of Xi' an University of Technology, Xi'an (2000)

4. Reboh, R., Reiter, J., Caschnig, J.: Development of a knowledge Based Interface to Hydrological Simulation Program, Final Report SRI International, SRI project 3477, Menlo Park, Ca (1982)

5. Palmer, R.N., Tull, R.M.: An Expert System for Drought Management planning. Journal of Computing in Civil Engineering, ASCE 1(4), 284-297 (1987) 
6. Palmer, R.N., Holmesk, J.: Operational Guidance During Drought: Expert System Approach. Journal of Water Resources Planning and Management 114(4), 647-666 (1988)

7. Raman, H.: An Expert System for Drought Management Planning. Journal of Computing in Civil Engineering, ASCE 1(4), 284-297

8. Clarkson, C., Hartigan, J.: Expert System Approach to Water Management Decisions. In: Proc Asce 6 th Conf on Compute. in Civil Engineering, ASCE, pp. 100-107 (1989)

9. Weng, W., Cai, X.: A Study on the Decision Support System of the Water Resources Planning in the Jing-Jin-Tang Economic District.京津塘水资源决策支持系统研究. Advances In Water Science (3) (1992)

10. Shangguan, Z., Shao, M., Xue, Z.: Decision Support System of Water Requirement Forecast for Dryland Crop. 旱地作物需水量预报决策辅助系统. Transactions of The Chinese Society of Agricultural Engineering 17(2), 42-46 (2001)

11. Shang, H., Wang, Z., Chai, P.: Research and Development of Water-saving Irrigation Database and Its Management System. 节水灌漑管理数据库及其管理系统的研究与开发. Research of Soil and Water Conservation 9(2), 97-101 (2002)

12. Zhang, L.: PengLou irrigation area Optimal Allocation of Water Resources and Irrigation Management Model. 彭楼灌区水资源优化分配及灌鹊管理模式研究. Master's thesis of North China Institute of Water Resources and Hydropower, ZhengZhou (2004)

13. Cui, Y., Li, Y.: Optimal Allocation of Irrigation Water Supply under Crop Water Stress Conditions. 作物缺水条件下灌溉供水量最优分配. Journal of Hydraulic Engineering (3), 37-42 (1997)

14. Wang, P.: Irrigation Area Optimization of Irrigation Mode and Decision Support System of Real-Time Irrigation. 灌区灌溉模式优选及实时灌溉决策支持系统. Master's thesis of North China Institute of Water Resources and Hydropower, ZhengZhou (2002) 